\title{
32. PALEOMAGNETISM OF BASALTS AND INTERLAYERED SEDIMENTS DRILLED DURING DSDP LEG 49 (N-S TRANSECT OF THE NORTHERN MID-ATLANTIC RIDGE)
}

\author{
A. M. Faller, Department of Earth Sciences, University of Leeds; \\ M. Steiner, University of Wyoming, Department of Geology, Laramie, Wyo.; \\ and \\ K. Kobayashi, Ocean Research Institute, University of Tokyo
}

\begin{abstract}
We report paleomagnetic results for Leg 49 obtained onboard Glomar Challenger and subsequently in the shore laboratories. The intensity of remanent magnetization of basaltic ocean crust fluctuates with depth at all sites; within-site variation of this property exceeds between-site variation. No significant differences in the remanence intensity of the upper ocean crust occur between magnetic anomalies 13 and $2^{\prime}$ or between groups of sites at latitudes $37^{\circ} \mathrm{N}, 45^{\circ} \mathrm{N}$, and $63^{\circ} \mathrm{N}$. An arithmetic mean intensity of $5.0 \times 10^{-3} \mathrm{emu} / \mathrm{cm}^{3}$ for all Leg 49 basalt specimens is close to previous average values for samples from the North Atlantic Ocean floor. Median destructive fields, weak field susceptibilities, and Königsberger ratios are comparable with previous results from ocean floor basalts. The Königsberger ratios show that remanence dominates the magnetization of the upper ocean crust. In seven out of eight holes, the sign of the stable inclination is appropriate to the magnetic anomaly. Values of stable inclination fluctuate with depth. At two sites, abrupt changes in stable inclination together with other paleomagnetic properties make it easy to define distinct magnetic units. At the other sites, it is more difficult to locate boundaries using magnetic evidence alone. Fewer magnetic units than petrographic units are identified in all cases.
\end{abstract}

\section{INTRODUCTION}

Paleomagnetic measurements on oceanic basement drilling in situ are extremely important in establishing the nature, thickness, and geometry of the magnetized bodies which generate marine magnetic anomalies. Leg 49 drilling took place over a wide geographic area, and the sites were carefully positioned to sample the centers of the sources of well-defined magnetic anomalies. The paleomagnetic results therefore constitute a significant extension to the pre-existing data.

The sites sampled form three groups: Holes 407, 408 and 409 on the west flank of the Reykjanes Ridge, Holes 410 and $410 \mathrm{~A}$ at latitude $45^{\circ} \mathrm{N}$, and Holes $411,412 \mathrm{~A}$, and 413 in the FAMOUS area. The immediate objectives of the shipboard studies were to identify variations of the magnetic properties with depth and use them to help distinguish lithologic boundaries. The broader objectives were to compare the magnetic data from different sites and to compare all these data with the results of previous DSDP drilling into basement, with measurements on dredged samples, and with theoretical predictions. These paleomagnetic studies are supported by rock magnetic studies which examine the sources of the remanence and its petrogenetic significance (see Day et al., this volume; Kobayashi et al., this volume).

\section{METHODS OF INVESTIGATION}

Paleomagnetic measurements were normally made on cylindrical cores, $2.54 \mathrm{~cm}$ in diameter and between 2.40 and
$2.54 \mathrm{~cm}$ high, obtained by drilling into the cut surface of the working half of the core. An arrow drawn on the top flat face of each cylinder indicated the up-hole direction. Samples were taken at a frequency of at least one per 1.5 meter section of core, whenever possible; they were taken only from pieces too long to have overturned in the core barrel. At Holes 411, $412 \mathrm{~A}$, and 413 , where the recovered basement material was sparse, a few thinner paleomagnetic samples, $1.0 \mathrm{~cm}$ in diameter and $2.4 \mathrm{~cm}$ high, were used in addition to those of standard size. At Hole 410, nine additional samples of $1.0 \mathrm{~cm}$ diameter, $1.0 \mathrm{~cm}$ high were taken from small basalt chunks in basalt-limestone breccia. These thinner cores were inserted into Styrofoam plugs for measurement. Shipboard measurements were made using a Digico balanced fluxgate spinner magnetometer, an alternating field (AF) demagnetizer with a two-axis tumbler, and a Schonstedt thermal demagnetizer in which the specimens were heated and then cooled in air. Three specimens known to be magnetically stable were measured on the Digico, which gave results very close to those obtained previously using a Schonstedt spinner magnetometer. Without a fluxmeter, any residual field in the cooling chamber of the thermal demagnetizer could not be measured, but tests on a granitic specimen suggested that such a field did not become important until the remanence intensity had decreased to $5 \times$ $10^{-5} \mathrm{emu} / \mathrm{cm}^{3}$. Subsequent measurements were made onshore using an identical Digico spinner, an AF demagnetizer with a two-axis tumbler, and a large thermal demagnetizer, where the field in the specimen chamber is 
less than 10 gamma and the cycle is carried out in oxygen-free nitrogen. Low field susceptibilities $(\chi)$ were measured using a commercial bridge. They were used together with the remanence intensities of the specimens to evaluate the Königsberger ratios $\left(Q_{n}\right.$, the ratio of the remanence intensity to the magnetization induced by the earth's present field).

\section{RESULTS}

The paleomagnetic results, which are reported in detail and plotted against depth in the site summary chapters, are summarized here for each of the eight holes. Table 1 shows the spread of values and the averaged value, where appropriate. The mean natural remanent magnetization (NRM) intensities are the arithmetic means giving each specimen unit weight. Mean stable inclinations have been calculated giving each specimen unit weight and using the method of Briden and Ward (1966), which compensates for the lack of absolute declination data. Table 2 further summarizes the NRM intensity data and compares the arithmetic means of Table 1 with those obtained by giving unit weight to every 9.5 meter core length, in an attempt to remove the effect of uneven distribution of specimens. $\chi$ and $Q_{n}$ are tabulated in Table 3. Figures 1,2 , and 3 are histograms of the NRM intensities, initial inclinations, stable inclinations, $\chi$ and $Q_{n}$.

\section{Hole $407\left(63^{\circ} 56.35^{\prime} \mathrm{N}, 30^{\circ} 34.56^{\prime} \mathrm{W}\right.$; magnetic anomaly} 13; $138 \mathrm{~m}$ of basalt cored)

We measured 30 basalt specimens and 4 samples of interbedded tuffs and demagnetized them to a stable end-point onboard Glomar Challenger. Onshore measurement of an additional 11 specimens confirmed the shipboard conclusion that there are three distinct magnetic units between depths of 320 and 459 meters. These units are recognized by their stable inclinations, but they also differ in their mean NRM intensities and stability to AF demagnetization (Table 1). The boundaries between the magnetic units coincide with petrologic boundaries, but in the interval occupied by the three magnetic units, 12 petrologic units are identified, each consisting of one to four flows. Each magnetic unit, therefore, includes several petrological units. A polarity change occurs between Units 1 and 2, at a depth of 340 meters. A few specimens from tuffaceous sediments interbedded with the basalts of Unit 1 have positive stable inclinations similar to those basalts. Units 2 and 3 are separated by a sampling gap from which only traces of sediment were recovered.

NRM intensities fluctuate with depth in all three units. Each unit responds differently to AF demagnetization. Unit 1 has the lowest median destructive field (MDF) of any group of specimens from Leg 49. Each of its specimens had normal initial inclination and high directional stability, but five specimens moved slightly toward shallower inclinations upon demagnetization, as though a weak, steep normal component was being removed. Unit 2 includes five specimens which have normal initial inclinations but change polarity early, and nine where an initial reversed inclination steepens, with little change in the relative declination. This also sugests removal of a steep normal component, and the behavior of the intensities supports it; 20 out of 30 reversed specimens show an increase in intensity after low field demagnetization. Unit 3 has higher directional stability than Unit 2, with a slightly higher average MDF. Several types of intensity change occurred upon thermal demagnetization, even within the same magnetic unit. In some cases, there were lowtemperature changes suggesting removal of an unstable component; in others, high-temperature changes occurred which may indicate two components of magnetization, one perhaps resulting from later oxidation.

The $\chi$ tends to decrease from Unit 1 to Unit 3 . This is partly reflected in lower values of $Q_{n}$ for Unit 1 and higher values for Unit 3, although both $\chi$ and $Q_{n}$ fluctuate appreciably. Though sparse, the $Q_{n}$ values show that remanence dominates the induced magnetization.

TABLE 1

Summary of Paleomagnetism Results for Basalts From Leg 49

\begin{tabular}{|c|c|c|c|c|c|c|c|c|c|c|c|c|}
\hline \multirow[t]{2}{*}{ Hole } & \multirow[t]{2}{*}{$\begin{array}{l}\text { Thickness } \\
\text { (m) }\end{array}$} & \multirow{2}{*}{$\begin{array}{c}\text { Number } \\
\text { of } \\
\text { Specimens }\end{array}$} & \multicolumn{3}{|c|}{$\mathrm{J}_{\mathrm{o}}\left(10^{-3} \mathrm{emu} / \mathrm{cm}^{3}\right)$} & \multirow[t]{2}{*}{ Polarity } & \multicolumn{3}{|c|}{$I\left({ }^{\circ}\right)$} & \multicolumn{3}{|c|}{ MDF (Oe) } \\
\hline & & & min. & $\max$. & mean & & $\min$. & $\max$. & mean $^{\mathrm{a}} \sigma$ & $\min$. & $\max$. & mean \\
\hline 407 & & & & & & & & & & & & \\
\hline Unit 1 & 20 & 9 & 3.1 & 17.7 & 6.0 & Normal & 39 & 73 & +673 & 20 & 100 & 50 \\
\hline Unit 2 & 48 & 15 & 2.1 & 5.3 & 3.0 & Reversed & 57 & 86 & -722 & 25 & 305 & 150 \\
\hline Unit 3 & 24 & 17 & 1.3 & 18.5 & 6.7 & Reversed & 35 & 78 & -624 & 60 & 500 & 175 \\
\hline Overall & 138 & 41 & 1.3 & 18.5 & 5.2 & & 35 & 68 & & 20 & 500 & 138 \\
\hline 408 & & & & & & & & & & & & \\
\hline Unit 1 & 15 & 8 & 0.3 & 2.7 & 1.1 & Normal & 52 & 65 & +592 & 160 & 310 & 230 \\
\hline Transition & 2 & 3 & 1.0 & 5.7 & 3.4 & Normal & 61 & 667 & +651 & 80 & 175 & 128 \\
\hline Unit 2 & 11 & 6 & 6.1 & 14.0 & 8.9 & Normal & 78 & 88 & +831 & 70 & 140 & 885 \\
\hline Overall & 32 & 17 & 0.3 & 14.0 & 4.3 & Normal & 52 & 88 & & 70 & 310 & 161 \\
\hline 409 & 230 & 76 & 0.6 & 17.0 & 5.1 & Reversed $^{\mathrm{b}}$ & 45 & 78 & -632 & 40 & 600 & 188 \\
\hline $410^{c}$ & 20 & 15 & 0.3 & 15.0 & 9.1 & Normal & 2 & 53 & & 160 & 525 & 242 \\
\hline $410 \mathrm{~A}$ & 42 & 28 & 1.6 & 7.9 & 3.2 & Normal & 1 & 49 & +213 & 140 & $>800$ & 290 \\
\hline 411 & 36 & 10 & 1.3 & 11.0 & 4.3 & Reversed & 8 & 68 & -407 & 35 & 180 & 112 \\
\hline $412 \mathrm{~A}$ & 130 & 26 & 0.7 & 8.5 & 3.7 & Reversed & 24 & 73 & -524 & 30 & 150 & 80 \\
\hline 413 & 2 & 3 & 8.0 & 16.6 & 12.3 & Reversed & 54 & 59 & -582 & 95 & 235 & 148 \\
\hline
\end{tabular}

Note: ${ }_{\mathrm{b}}^{\mathrm{a}}$ The mean inclination and standard deviation $(\sigma)$ have been calculated by the method of Briden and Ward (1966).

b Two specimens suspected of being misoriented have been ignored.

${ }^{c}$ Mean values have been used for both groups of small specimens and unit weight given to each mean. 
TABLE 2

Summary of NRM Intensity Data for Basalts From Leg 49

\begin{tabular}{|c|c|c|c|c|c|}
\hline Site & $\begin{array}{l}\text { Number of } \\
\text { Specimens }\end{array}$ & $\begin{array}{c}\text { Specimen } \\
\text { Mean Intensity } \\
\left(10^{-3} \mathrm{emu} / \mathrm{cm}^{3}\right)\end{array}$ & $\begin{array}{c}\text { Number of } \\
\text { Cores }\end{array}$ & $\begin{array}{c}\text { Core Mean } \\
\text { Intensity } \\
\left(10^{-3} \mathrm{emu} / \mathrm{cm}^{3}\right)\end{array}$ & $\begin{array}{c}\text { Log Mean } \\
\text { Intensity } \\
\left(10^{-3} \mathrm{emu} / \mathrm{cm}^{3}\right)\end{array}$ \\
\hline 407 & 41 & 5.2 & 12 & 5.2 & \\
\hline 408 & 17 & 4.3 & 4 & 4.3 & \\
\hline 409 & 76 & 5.1 & 24 & 5.7 & \\
\hline 410 & 15 & 9.1 & 4 & 9.2 & \\
\hline $410 \mathrm{~A}$ & 28 & 3.2 & 6 & 3.0 & \\
\hline 411 & 10 & 4.3 & 5 & 4.5 & \\
\hline $412 \mathrm{~A}$ & 26 & 3.7 & 13 & 4.1 & \\
\hline 413 & 3 & 12.3 & 1 & 12.3 & \\
\hline $\begin{array}{l}\text { All RR } \\
\text { sites }\end{array}$ & 134 & 5.0 & 40 & 5.5 & \\
\hline $\begin{array}{l}\text { All } 45^{\circ} \mathrm{N} \\
\text { sites }\end{array}$ & 43 & 5.2 & 10 & 5.5 & \\
\hline $\begin{array}{l}\text { All } \\
\text { FAMOUS }\end{array}$ & & & & & \\
\hline sites & 39 & 4.5 & 19 & 4.7 & \\
\hline $\begin{array}{l}\text { All } \\
\text { sites }\end{array}$ & 216 & 5.0 & 69 & 5.3 & 3.6 \\
\hline
\end{tabular}

Hole $408\left(63^{\circ} 22.63^{\prime} \mathrm{N}, 28^{\circ} 54.71^{\prime} \mathrm{W}\right.$; magnetic anomaly 6 ; $32 \mathrm{~m}$ of basalt cored)

We deduced from 17 specimens that there are two magnetic units between 323 and 361 meters, separated by a narrow transition region probably caused by reheating of the lower unit when the upper unit was extruded onto it. At least nine flows or groups of flows are present in the same interval, and the base of the upper magnetic unit (Unit 1) coincides with a petrologic boundary. NRM intensities, stable inclinations, and MDFs all differ between the two units (Table 1). All specimens have normal polarity, appropriate to the sign of the magnetic anomaly, and their high directional stability upon demagnetization suggests that no low-stability component of remanence was present.

Four specimens (two from Unit 1, one from Unit 2, and one from the transitional region) show very little directional change when heated to $400^{\circ} \mathrm{C}$ in $50^{\circ} \mathrm{C}$ increments, and very similar steady decrease of intensity. The only difference is a slightly higher blocking temperature for a specimen from Unit $1\left(450^{\circ} \mathrm{C}\right.$, compared with $\left.430^{\circ} \mathrm{C}\right)$, which may indicate that Unit 1 is more oxidized than Unit 2. Again, $\chi$ values are low and give rise to high $Q_{n}$ values (Table 3).

Hole $409\left(62^{\circ} 36.98^{\prime} \mathrm{N}, 25^{\circ} 57.17^{\prime} \mathrm{W}\right.$; magnetic anomaly $2^{\prime}$; $230 \mathrm{~m}$ of basalt cored)

All the magnetic properties except polarity fluctuate rapidly, and separate units cannot be defined from them, although the number of specimens and the depth sampled are greater than for any other Leg 49 site. In retrospect it is apparent, however, that at least one sudden change in inclination occurs close to a geochemical boundary. Fifty-eight flow groups are recognized petrologically; the magnetic results do not contradict this, but could not establish it on their own. All specimens show reversed polarity, appropriate to the Matuyama reversed interval. About half move to steeper inclinations upon progressive demagnetization, and most show a slight intensive increase in the early stages, as do reversed specimens at Hole 407. Thermal demagnitization indicates blocking temperatures between $410^{\circ} \mathrm{C}$ and $430^{\circ} \mathrm{C}$, similar to those at Holes 407 and 408, which may imply that all the specimens contain similar ferromagnetic minerals. Higher than average $\chi$ and lower than average $Q_{n}$ occur in the uppermost 20 meters of the hole (Table 3 ).

Hole $410\left(4^{\circ} 30.51^{\prime} \mathrm{N}, 2^{\circ} 28.56^{\prime} \mathrm{W}\right.$; magnetic anomaly 5 ; $20 \mathrm{~m}$ of basalt-limestone breccia cored)

The basement drilled here consists of basal-limestone breccia. The mean NRM intensity of the basalt specimens is high $\left(9.1 \times 10^{-3} \mathrm{emu} / \mathrm{cm}^{3}\right)$, and tha of the limestones is around $2 \times 10^{-5} \mathrm{emu} / \mathrm{cm}^{3}$. Because they are from breccia, it is surprising that most of the specimens have stable inclinations which are not random, but appropriate to the sign of the magnetic anomaly and within a range similar to those from the flows sampled in Hole 410A. Further, a petrographic boundary at 366 meters coincides with an abrupt change of stable inclination. On the other hand, the stable normal inclinations are shallow for the latitude, while three specimens of chalk from 35 meters above the basement have stable inclinations between $55^{\circ}$ and $69^{\circ}$, comparable to the predicted $64^{\circ}$. All specimens have very high directional stability. Basalts and limestones show similar intensity decay upon A.F. demagnetization. Remanence dominates induced magnetization, even in the limestone (Table 3).

Conglomerate tests on two groups of small basalt chunks ( $1 \mathrm{~cm}$ diameter, $1 \mathrm{~cm}$ height) introduce more diversity into the magnetic properties, but the stable inclinations of both groups are not completely random (see Hole Summary). The combined evidence from basalt and limestone specimens may indicate brecciation of a hot lava flow with imprinting of a coherent remanence when the breccia came to rest, but the possibility of later remagnetization also remains. 
TABLE 3

NRM Intensities $\left(J_{0}\right)$, Volume Susceptibilities $(\mathrm{x})$, and Königsberger Ratios $\left(Q_{n}\right)$ for Basalts from Leg 49

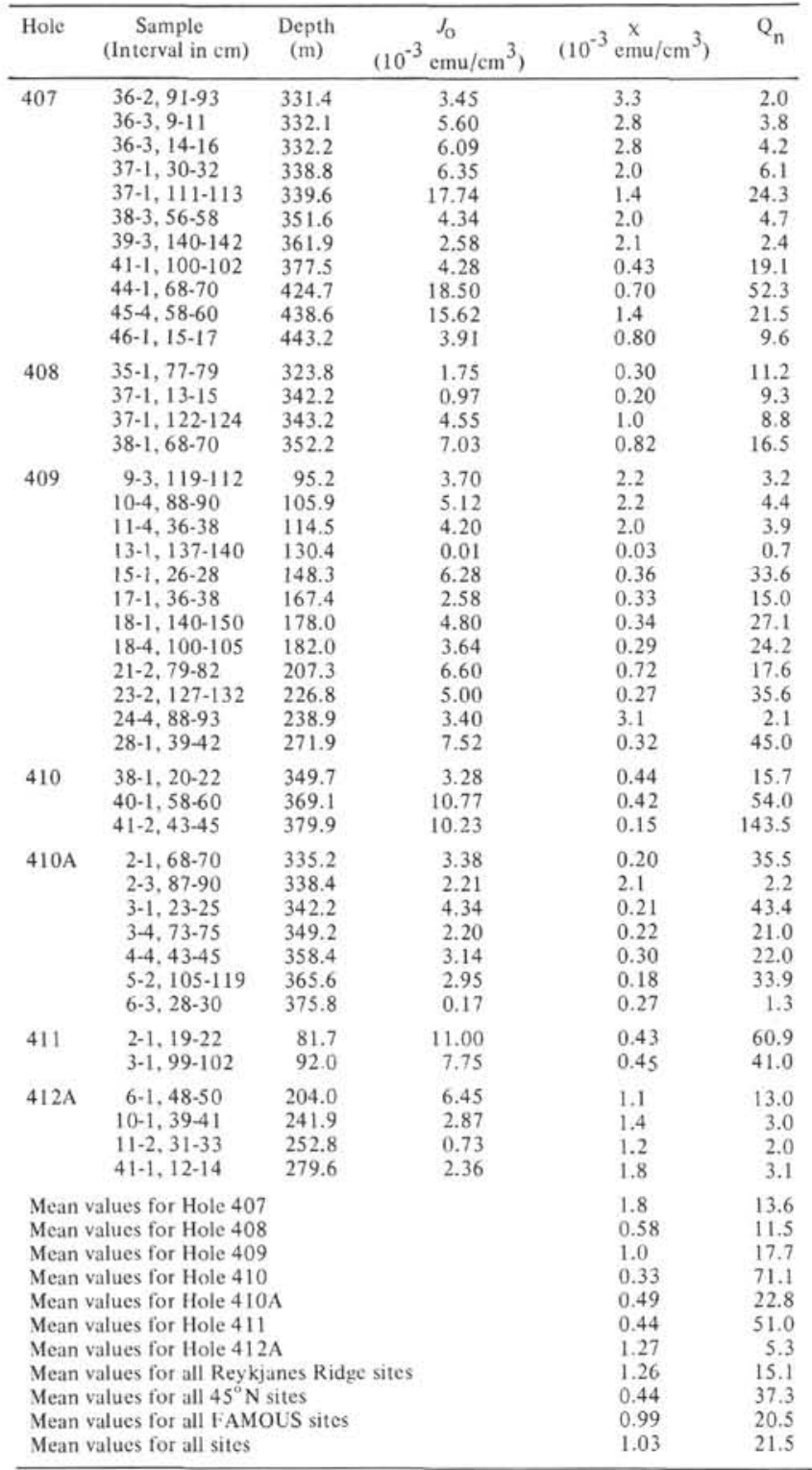

Hole $410 \mathrm{~A}\left(4^{\circ} 30.51^{\prime} \mathrm{N}, 2^{\circ} 28.56^{\prime} \mathrm{W}\right.$; magnetic anomaly $5 ; 42 \mathrm{~m}$ of basalt cored)

In this companion hole to 410 , only 110 meters away, thin flows, rather than breccia, were drilled. At least one magnetic boundary is indicated by a change in inclinations and MDFs, in 44 meters of basalt which is petrographically uniform; this may correspond to the boundary tentatively identified in Hole 410. No correlation is evident between NRM intensity and depth; the mean intensity is about a third of the mean for basalts at Hole 410, and the range of intensities at Hole 410A is less than at any other Leg 49 hole. Inclinations are all positive, in agreement with the magnetic anomaly, but they become shallower with depth, and reach values far from the predicted $64^{\circ}$. Directional stability is very high, and some very high MDF's, around $500 \mathrm{Oe}$, bring the mean MDF to $250 \mathrm{Oe}$, the highest for any Leg 49 site. $\chi$ tends to be low and $Q_{n}$ high (Table 3).
Hole $411\left(36^{\circ} 45.97^{\prime} \mathrm{N}, 33^{\circ} 23.30^{\prime} \mathrm{W}\right.$; magnetic anomaly 2 ; $36 \mathrm{~m}$ of basalt cored)

The sampling density is low, but a change in magnetic directions and properties occurs across the main petrographic boundary. The reversed stable inclinations are appropriate to both the magnetic anomaly and the axial dipole inclination of $56.2^{\circ}$. One of eight specimens changed sign upon demagnetization; the others have very high directional stability. MDFs are fairly low, $\chi$ is low, and $Q_{n}$ is high (Tables 1 and 3).

\section{Hole $412 \mathrm{~A}\left(36^{\circ} 33.74^{\prime} \mathrm{N}, 33^{\circ} 09.96^{\prime} \mathrm{W}\right.$; magnetic anomaly} 2'; $130 \mathrm{~m}$ of basalt cored)

It is again difficult to distinguish magnetic units in the 130-meter interval, although a chalk layer is present within the basalt. A single chalk specimen has NRM intensity $1.6 \times$ $10^{-5} \mathrm{emu} / \mathrm{cm}^{3}$ and a stable inclination of $-30^{\circ}$. Bedding in the chalk indicates that it had been tilted, but when the magnetic direction is corrected for this the inclination becomes even shallower $\left(-10^{\circ}\right)$ and further from the predicted value. The uppermost basalt specimen is normal and directionally stable $\left(\mathrm{I}=+60^{\circ}\right)$, but the others have stable reversed inclinations appropriate to the anomaly and to the latitude $\left(I=-52^{\circ} \pm 4^{\circ}\right)$. Some of the lowest intensity specimens are extremely viscous, with very low MDFs, and change direction readily upon demagnetization; these are usually porphyritic in texture. Others with high NRM intensity are directionally stable, with higher MDFs; these are aphyric or sparsely phyric. The two types alternate down the hole, and no continuous sequence is longer than 17 meters. Thermal demagnetization of five specimens indicates at least three blocking temperatures. The mean $Q_{n}$ is lower than at other Leg 49 sites.

Hole $413\left(36^{\circ} 32.59^{\prime} \mathrm{N}, 3^{\circ} 10.50^{\prime} \mathrm{W}\right.$; magnetic anomaly $2^{\prime}$; $1 \mathrm{~m}$ of basalt cored)

The three specimens from this low-recovery site have higher than average NRM intensities, reversed polarity, high directional stability, and stable inclinations appropriate to the latitude, which suggest in-situ sampling, although the basalt is believed to be from reworked talus.

\section{DISCUSSION}

The time interval represented by sampling at any Leg 49 site is probably only a fraction of a magnetic polarity interval, since maximum penetration into basement in any hole was 230 meters. However, because sites were situated at different distances from the Mid-Atlantic Ridge, time variations of properties can be studied over much longer periods, dating back to magnetic anomaly 13 . The three Reykjanes Ridge holes are on anomalies 13,6 , and $2^{\prime}$, so that basalts from 36 m.y. to $2.3 \mathrm{~m}$.y. old have been sampled at the same latitude. We can compare holes close to each other, i.e., Hole 410 with Hole 410A; the FAMOUS holes with each other; sites of similar ages but at different latitudes, i.e., the FAMOUS holes with the young Reykjanes Ridge hole 409; and the holes at $45^{\circ} \mathrm{N}$ on anomaly 5 with Hole 408 on the west flank of the Reykjanes Ridge on anomaly 6 . We therefore examine 

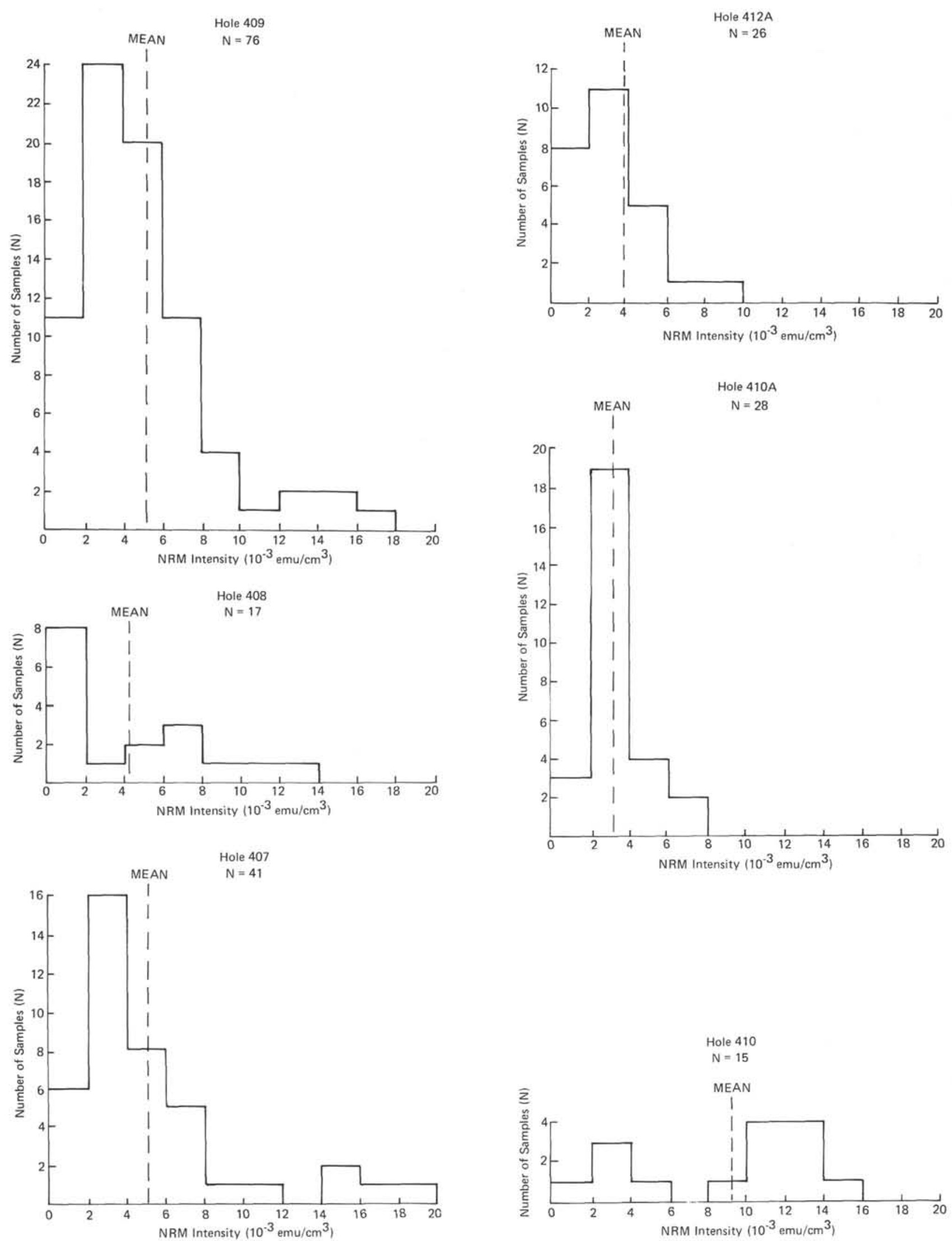

Figure 1. Histograms of NRM intensities of basalt specimens from Leg 49: (a) arithmetic (b) logarithmic. $N$ denotes the number of specimens. Dashed lines denote arithmetic means. 

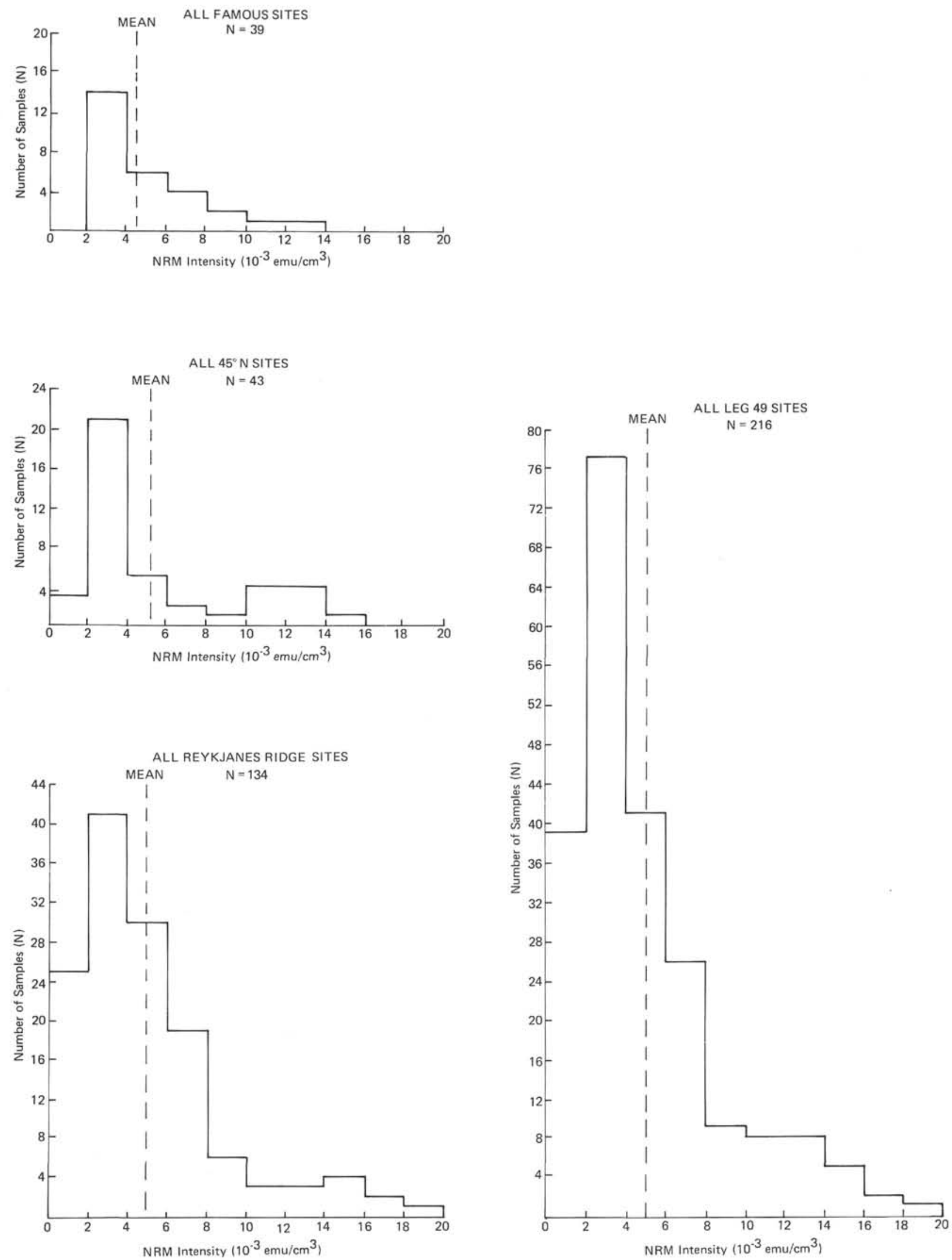

Figure 1. Continued. 

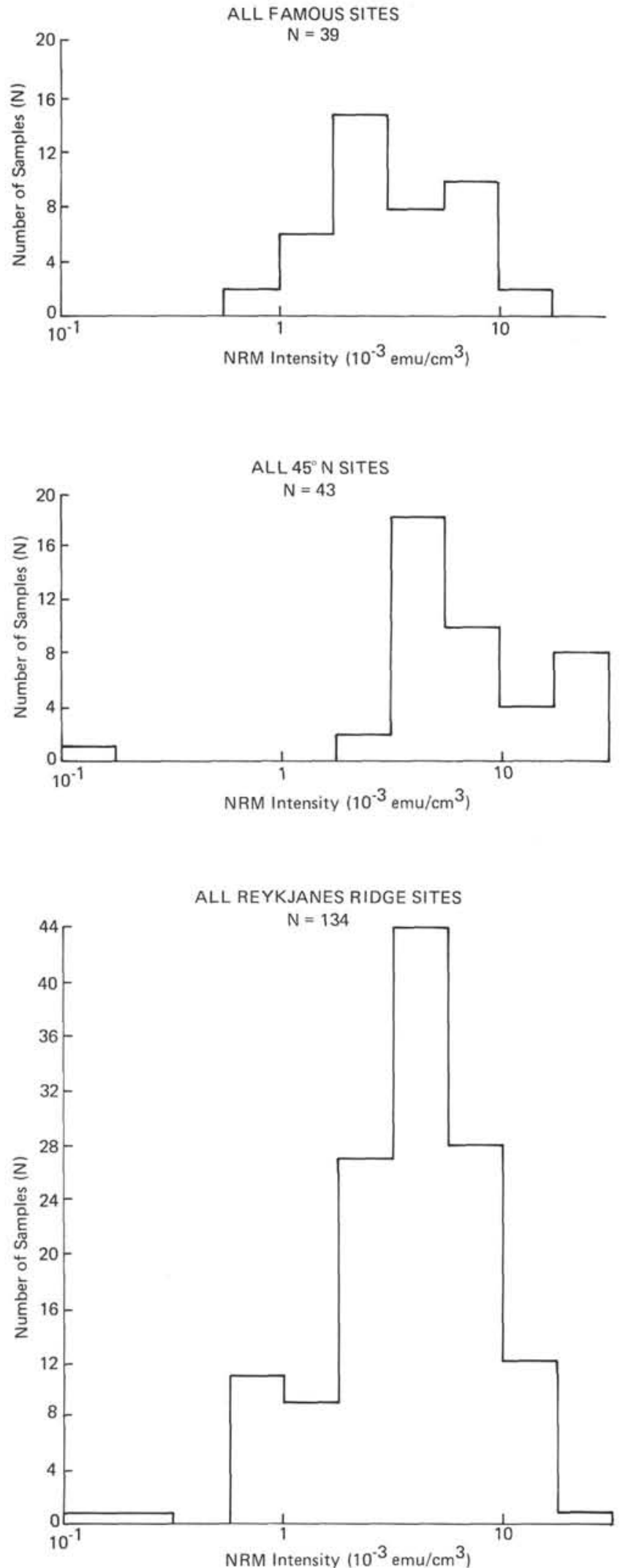

Figure 1. Continued.

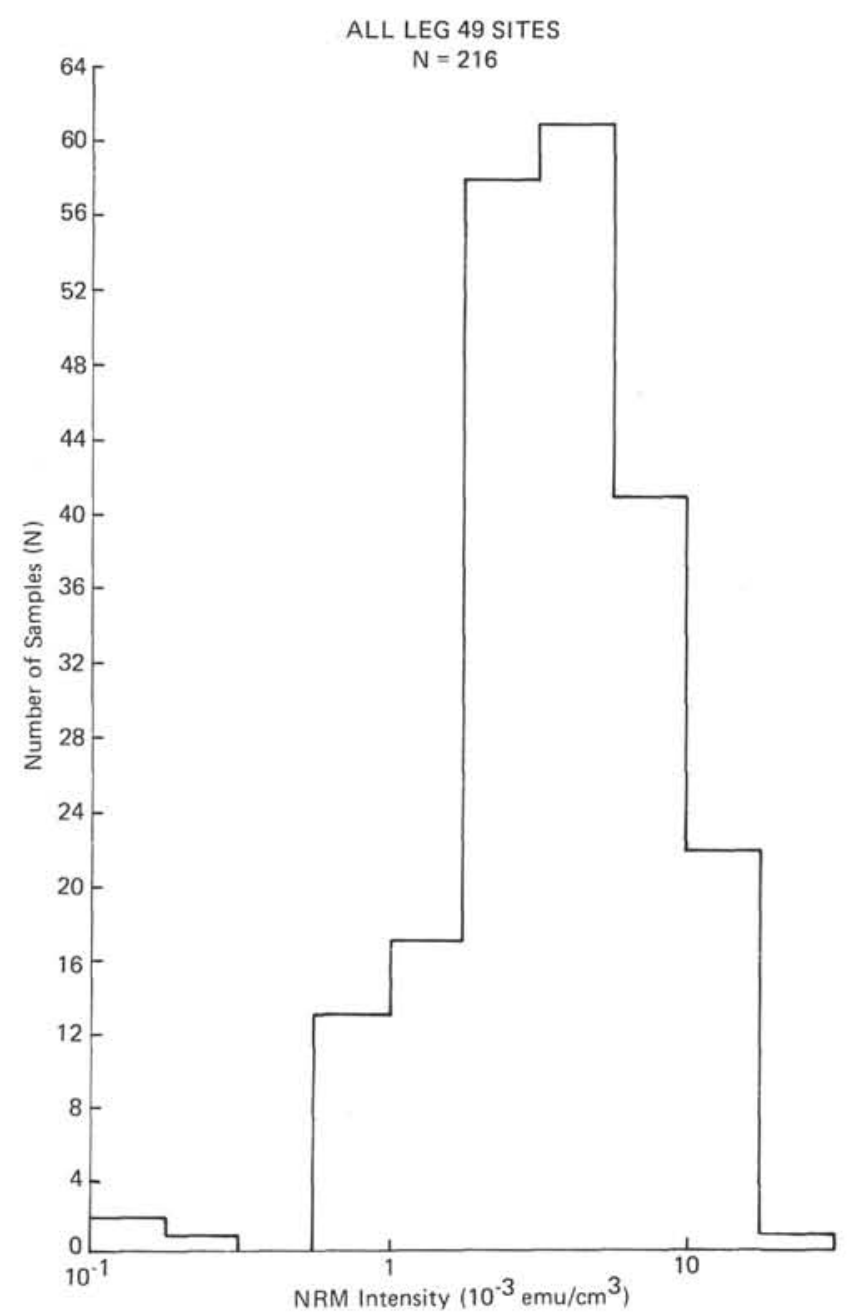



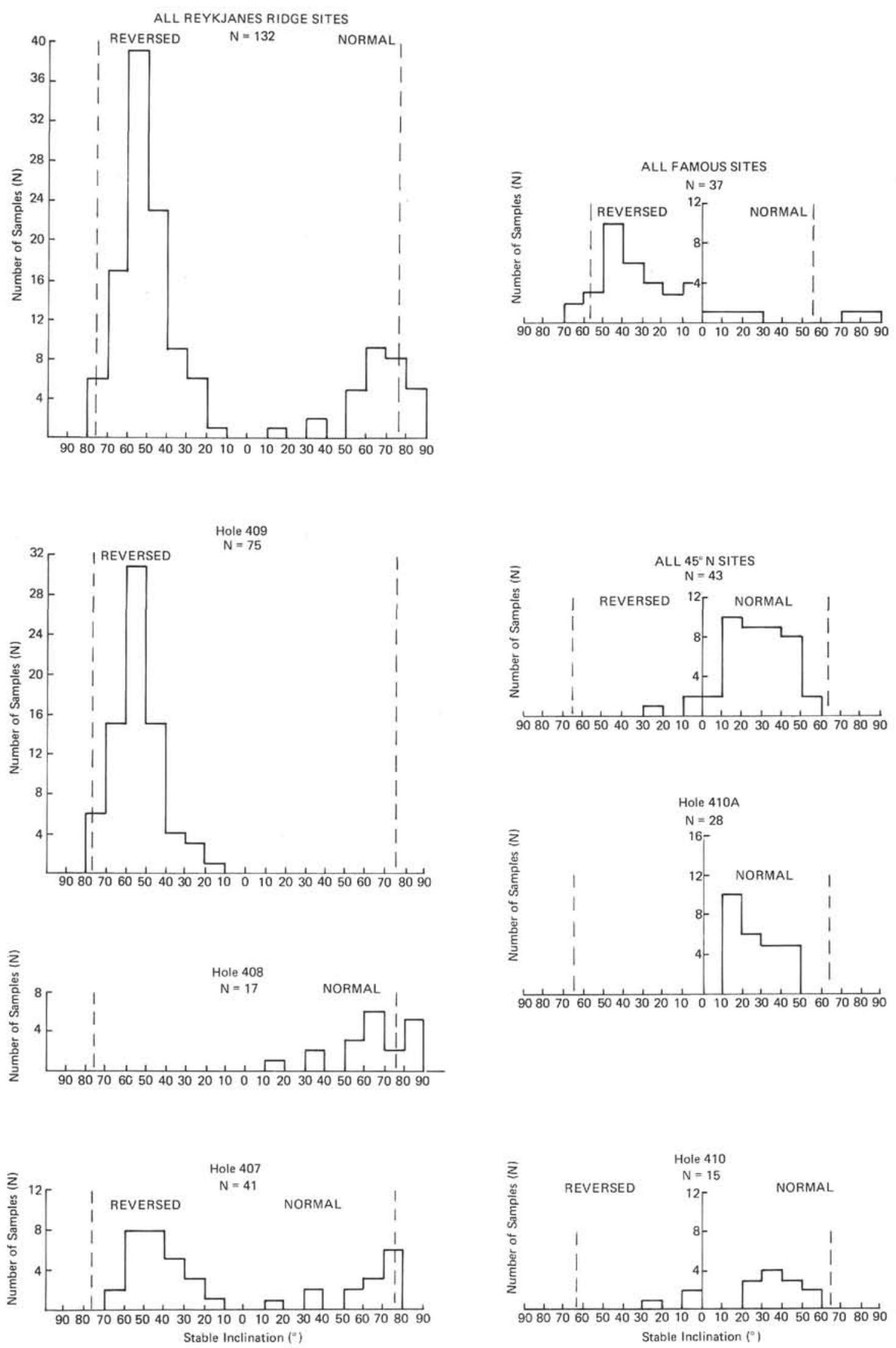

Figure 2. Histograms of inclinations of basalt specimens from Leg 49: (a) initially, (b) after demagnetization to a stable end-point. $N$ denotes the number of specimens. Dashed lines indicate the inclinations predicted for the present latitudes of the sites by the centered axial dipole model. 

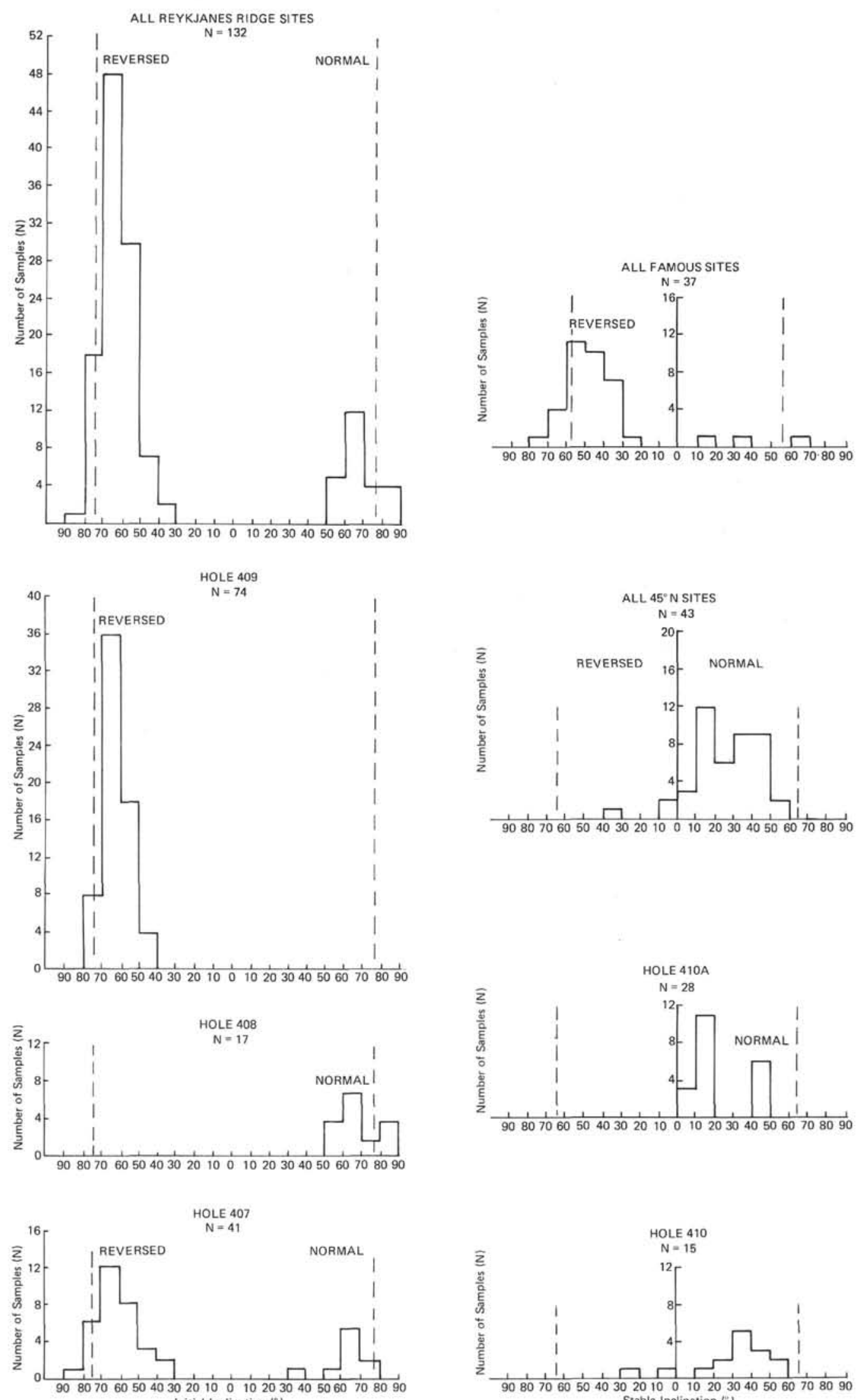

Figure 2. Continued.

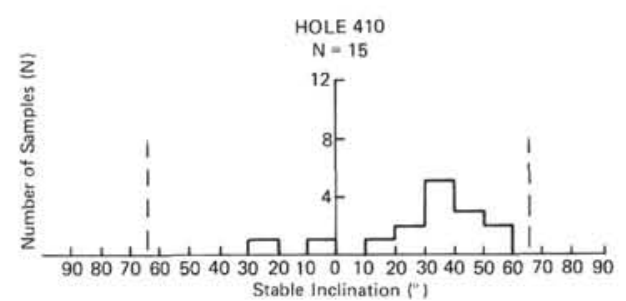



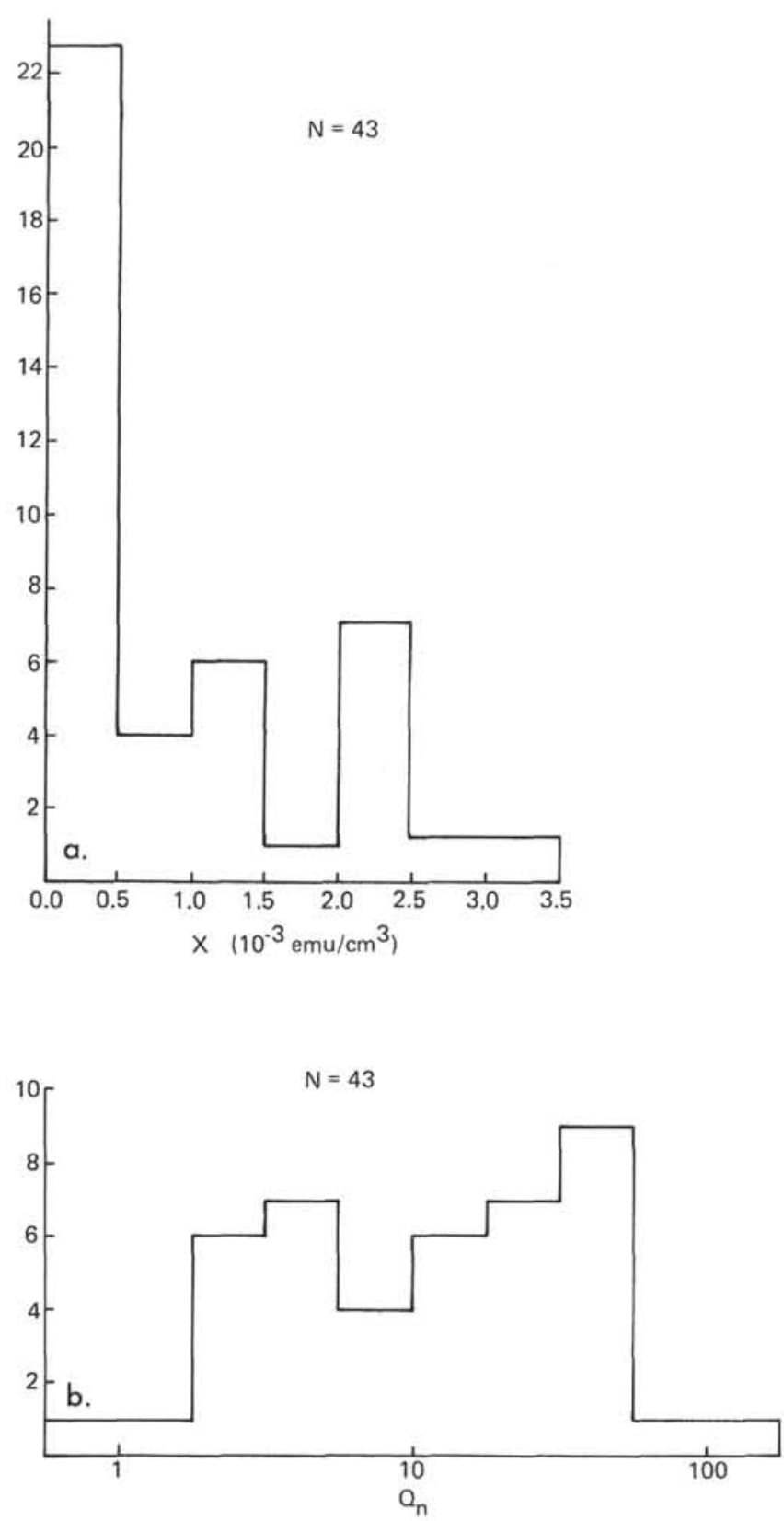

Figure 3. (a) Arithmetic histogram of weak field volume susceptibilities $(\chi)$ for basalt specimens from Leg 49. (b) Logarithmic histogram of Königsberger ratios (Qn) for the same specimens. $N$ denotes the number of specimens.

our results for magnetic properties typical of the North Atlantic basement as a whole, and also for variations with age and latitude.

Basalts from all the holes have weak low-field susceptibility ( $\chi$ ); the mean $Q_{n}$ for 44 specimens is 21 (Table 3 and Figure 3 ). This demonstrates that remanence dominates the induced magnetization in the ocean crust, as it does in basalts from previous DSDP holes in several oceans and in dredged specimens (Lowrie, 1977) and in basalts from the FAMOUS area (Johnson and Atwater, 1977; Ryall et al., 1977). The NRM intensities must therefore contribute to the observed magnetic anomalies.
In all Leg 49 holes, NRM intensities fluctuate with depth and do not show systematic trends in the intervals sampled. At Holes 407 and 408 , distinct magnetic units are obvious; these comprise sections of more than 10 meters of basalt with significant differences between their mean stable inclinations, which reflect time variations of the earth's magnetic field. These units also differ in their NRM intensities and MDFs, possibly because of variations in ferromagnetic constituents, grain size, and oxidation state. Boundaries between them are also lithologic boundaries. The magnetic units at Holes 407 and 408 are comparable with Magnetic Superunits B of Ryall et al. (1977) in the deep holes of Leg 37. At Hole 409, similar inclinations of a few consecutive specimens from flows indicate that they were erupted within a period short enough to give an instantaneous sample of the secular variation of the geomagnetic field, but the exact number of magnetic units cannot be determined on paleomagnetic evidence alone. The lack of absolute declination data is a handicap here. At Holes 410, 410A, 411 , and $412 \mathrm{~A}$, changes in stable inclination occur close to petrographic boundaries, but not as obviously as at Holes 407 and 408 .

NRM intensity data are summarized in Tables 1 and 2 and Figure 1. At the Reykjanes Ridge holes, the between-site differences are small compared with the within-site differences, so that the intensity data show no significant differences between anomalies 13 and $2^{\prime}$. The mean intensity at the young Hole 409 is somewhat higher than the mean of the young FAMOUS sites, but because of the large scatter and the stronger magnetizing field at the higher latitude, this is not significant. The greatest difference in hole mean intensities arises between the two closest holes, 410 and $410 \mathrm{~A}$, only 110 meters apart. Their mean intensities differ by a factor of three, but this may arise from sampling breccia at Hole 410 and flows at Hole 410A. The mean intensity of the basalts from these two holes on anomaly 5 is slightly greater than the mean of basalts from Hole 408 on anomaly 6 at higher latitude; both means have a large standard deviation.

The arithmetic means for the three groups of sites (Reykjanes Ridge, $45^{\circ} \mathrm{N}$, and FAMOUS) are close enough to each other for an overall mean to be considered representative of the upper 230 meters of the North Atlantic Ocean crust. The histograms of Figure $1 \mathrm{~b}$ show that the NRM intensities of all Leg 49 basalt specimens follow an approximately log-normal distribution similar to that published by Lowrie (1977) for 301 DSDP samples drilled before Leg 49. The arithmetic mean for Leg 49 is $5.0 \times 10^{-3}$ $\mathrm{emu} / \mathrm{cm}^{3}$, and the corresponding logarithmic mean is $3.6 \times$ $10^{-3} \mathrm{emu} / \mathrm{cm}^{3}$. Arithmetic means are overestimates for the source strength of the magnetic anomalies, since no allowance is made for scatter in the inclinations of the individual specimens, for voids and non-magnetic material in the core, or for unstable viscous components, the effect of which is discussed by Harrison (1976). Arithmetic means are, however, convenient for comparing our NRM intensities with much of the published data, particularly where dredged or unoriented samples are concerned.

Our Reykjanes Ridge intensities are much lower than the values calculated by Talwani et al. (1971) to explain the magnetic anomalies along and across the ridge. Talwani et al. required intensities of $30 \times 10^{-3} \mathrm{emu} / \mathrm{cm}^{3}$ on the ridge axis, $12 \times 10^{-3} \mathrm{emu} / \mathrm{cm}^{3}$ at $75 \mathrm{~km}$ from it, and $7 \times 10^{-3} \mathrm{emu} / \mathrm{cm}^{3}$ at 
$100 \mathrm{~km}$, over anomaly 5 . They deduced that the source of the magnetic anomalies is a uniformly magnetized layer of basement (Layer 2A) only 400 meters thick. Our measurements do not show a decrease of NRM intensity with increasing distance from the ridge, and our mean intensity from 230 meters of basement at Site 409 is less than half the value of Talwani et al. for $75 \mathrm{~km}$. As Figure 1a shows, only 10 of our 134 Reykjanes Ridge specimens have intensities above $12 \times 10^{-3} \mathrm{emu} / \mathrm{cm}^{3}$, and the implication is either that the magnetized layer is thicker than 400 meters or that its intensity increases suddenly below 230 meters.

Our mean NRM intensities from $45^{\circ} \mathrm{N}$ are comparable to the intensities measured by Irving et al. (1970) on dredged samples from the flanks of the Mid-Atlantic Ridge at the same latitude. These dredged samples had even lower weak field susceptibilities than our basalts.

Leg 49 mean intensity from the FAMOUS area is within the range of $(3.6 \pm 2.3) \times 10^{-3} \mathrm{emu} / \mathrm{cm}^{3}$ reported by Ryall et al. (1977), this being the core mean of all basalts from Leg 37 , where the deepest penetration was 582 meters. When the NRM intensities of drilled and dredged basalts from the FAMOUS area are plotted against distance from the ridge axis (fig. 3 of Johnson and Atwater, 1977), they decrease rapidly from $24 \times 10^{-3} \mathrm{emu} / \mathrm{cm}^{3}$ and level off at $4 \times 10^{-3}$ $\mathrm{emu} / \mathrm{cm}^{3}$ at $10 \mathrm{~km}$. Our mean values for Holes 411 and $412 \mathrm{~A}$ plot very close to this curve, but the three specimens from Hole 413 have anomalously high intensity. Our NRM intensities from FAMOUS are also broadly consistent with the analysis by Macdonald (1977) of the deep-tow magnetic anomalies in the area. He finds that the intensity of magnetization falls to $1 / \mathrm{e}$ of the central anomaly value in less than $0.6 \mathrm{~m}$.y., and predicts intensities of between 4 and $8 \times$ $10^{-3} \mathrm{emu} / \mathrm{cm}^{3}$ at anomaly $2^{\prime}$; these constitute the central part of our measured range (Figure 1). Our few susceptibility values (Table 3) are lower than those of Johnson and Atwater (1977), but are insufficient to permit conclusions about variation with distance from the ridge axis. The two $Q_{n}$ values from Hole 411 are much higher than those from Hole $412 \mathrm{~A}$, which are close to the value of 3 found by Johnson and Atwater for crust of the same age.

The overall mean intensity for Leg 49 basalts is within 10 per cent of that published by Lowrie (1977) for 64 samples from 10 North Atlantic sites. Leg 49 data therefore agree with the tentative conclusion from table 2 of Lowrie (1977) that the intensity of magnetization of the North Atlantic Ocean floor is similar to that of the Indian and Pacific Ocean floors and the Caribbean sea floor, but greater than the intensity of the South Atlantic and Antarctic Ocean floors. Data for the North Atlantic greatly exceed data for any other ocean, and therefore the mean intensity for other oceans may be less representative of the magnetization of Layer 2 .

Figures $2 \mathrm{a}$ and $2 \mathrm{~b}$ show the distribution of inclinations before and after demagnetization, and the inclinations predicted by the axial dipole field model. The spread of stable inclinations is always less than that of initial inclinations, although most specimens have high directional stability. At Holes 407 and 409 a steep, unstable normal component was often removed early in the demagnetization process. Such a component, which may be induced by drilling or may arise from partial remagnetization in the earth's present field, has been observed at previous drill sites (Prevot et al., 1976;
Ryall et al., 1977). There is no evidence for this component at Hole 408 or at the lower latitude sites. All the specimens from Holes 410, 410A, 411, and 413 and some from Hole $412 \mathrm{~A}$ show very high directional stability; the remainder from Hole 412A are extremely viscous, and changed direction readily before reaching a stable inclination.

At all holes except 407 , the polarity of the stable remanence agrees with the sign of the magnetic anomaly. A polarity change occurs about a third of the way down Hole 407 , so that the basalt sampled under a positive anomaly is mainly of reversed polarity. This could be explained if the dominant source of the anomaly is deeper than 130 meters, or if the magnetized bodies are wedge-shaped rather than rectangular. A similar situation occurs in Hole 395A of Leg 45 (Johnson, in press), and polarity reversals occur in at least one hole of Leg 37 (Ryall et al., 1977). We find no evidence for magnetization during a transition of the earth's magnetic field. A few specimens of associated sediments at Holes 407 and 410 have stable inclinations close to the basalts, but a single chalk specimen from Hole $412 \mathrm{~A}$ is anomalous.

Only in the FAMOUS area do our stable inclinations agree closely with the axial dipole field prediction; elsewhere they appear to be shallow for the latitude. Prevot et al. (1976) and Johnson and Atwater (1977) also report agreement between the inclinations of oriented samples from FAMOUS and the predicted value, but Ryall et al. (1977) find that shallow inclinations predominate down Holes 332 and 333 of Leg 37. Lowrie (1977) shows that there is no overall tendency for DSDP basalt inclinations to be systematically shallow or steep, although discrepancies often occur between predicted and observed inclinations. At six of our Leg 49 sites it is unlikely that secular variation has been averaged out (Luyendyk, this volume); this, together with experimental uncertainty, may well account for the scatter in the stable inclinations and the discrepancies between them and the predicted value.

In conclusion, the Leg 49 results show that paleomagnetic properties of the North Atlantic basaltic crust fluctuate with depth down to 230 meters. Intensity of magnetization is comparable to previous measured values, and magnetization sufficient to produce the observed magnetic anomalies is unlikely to reside entirely in a thin Layer $2 \mathrm{~A}$. The high stability of the remanence and the general agreement between polarity and magnetic anomaly are convincing evidence that the original thermoremanent magnetization of the ocean crust has not been obscured.

\section{ACKNOWLEDGMENT}

We thank Dr. G.E. Morgan for helpful discussion during the shore-based work and for constructive criticism of this manuscript.

\section{REFERENCES}

Briden, J.C. and Ward, M.A., 1966. Analysis of magnetic inclination in borecores, Pure and Applied Geophysics, v. 63, p. 133.

Harrison, C.G.A., 1976. Magnetization of the oceanic crust, Geophysical Journal of the Royal Astronomical Society, v. 47, p. 257.

Irving, E., Robertson, W.A., and Aumento, F., 1970. The mid-Atlantic ridge near $45^{\circ} \mathrm{N}$ : VI. Remanent intensity, susceptibility and iron content, Canadian Journal of Earth Sciences, v. 7, p. 226. 
Johnson, H.P., in press. Paleomagnetism of igneous rock samples - DSDP Leg 45. In Melson, W.G., Rabinowitz, P.D., et al., Initial Reports of the Deep Sea Drilling Project, v. 45: Washington (U.S. Government Printing Office).

Johnson, H.P. and Atwater, T., 1977. Magnetic study of basalts from the Mid-Atlantic Ridge, lat. $37^{\circ} \mathrm{N}$, Geological Society of America Bulletin, v. 88 , p. 637.

Lowrie, W., 1977. Intensity and direction of magnetization in oceanic basalts, Journal of the Geological Society of London, v. 133 , p. 61.

Macdonald, K.C., 1977. Near-bottom magnetic anomalies, asymmetric spreading, oblique spreading, and tectonics of the
Mid-Atlantic Ridge near lat. $37^{\circ} \mathrm{N}$, Geographical Society of America Bulletin, v. 88 , p. 541.

Prevot, M., Lecaille, A., Francheteau, J., and Hekinian, R., 1976. Magnetic inclination of basaltic lavas from the Mid-Atlantic Ridge near $37^{\circ} \mathrm{N}$, Nature, v. 259 , p. 649.

Ryall, P.J.C., Hall, J.M., Clark, J., and Milligan, T., 1977. Magnetization of oceanic crustal layer 2 - results and thoughts after DSDP Leg 37, Canadian Journal of Earth Sciences, v. 14, p. 684 .

Talwani, M., Windisch, C., and Langseth, M.G. Jr., 1971. Reykjanes Ridge crest: A detailed geophysical study, Journal of Geophysical Research, v. 76, p. 473. 